\title{
The Techno-literacy Practices of Young Children from Diverse Backgrounds
}

\author{
NICOLA FRIEDRICH \\ Ontario Institute for Studies in Education/University of Toronto \\ LAURA TEICHERT \\ University of British Columbia \\ ZIPPORAH DEVADAS \\ British Columbia School District 35
}

\begin{abstract}
To complicate the notion of a digital divide along economic and cultural lines, this paper describes techno-literacy practices within the homes of children from diverse backgrounds. Data were drawn from two ethnographic case studies examining the home literacy practices of pre-school aged children. Participants were three Karen refugee families and two English-speaking, middle-class families. The findings suggest that children initiate interactions with digital tools within the cultural and economic landscapes of the home. In so doing, they develop operational competencies to access digital texts in order to scaffold their current learning and enable their participation in $21^{\text {st }}$ century society.
\end{abstract}

Keywords

digital literacy practices, early childhood literacy, family literacy, refugee families

\section{Introduction}

This paper explores young children's techno-literacy experiences in the home prior to their arrival in formal schooling. The perspective taken is inspired by early descriptive research into the language and literacy experiences of children from culturally, linguistically, and economically diverse backgrounds (e.g., Gregory, 2001; Heath, 1983; Purcell-Gates, 1996; Taylor, 1983; Taylor \& Dorsey-Gaines, 1988). Recent large-scale investigations of digital technologies in the home have introduced the notion of a divide along economic and cultural lines regarding families' access to and use of digital tools (e.g., Gutnick, Robb, Takeuchi, \& Kotler, 2011; Rideout, 2011). It is this observation that inspired us to draw data from our own ethnographic case studies to demonstrate the nature of young children's early literacy experiences with digital tools prior to their entry into formal schooling and to highlight commonalities in digital practices within the cultural and economic landscapes of their homes. We used the following research questions to guide our analysis of the data: What digital tools/texts do children from diverse backgrounds (i.e., family composition, socioeconomic status, home language use) have access to within the home? What literacy practices do these tools/texts mediate? How are these practices enacted? By adopting a practice approach, the findings of this study add to the literature regarding young children and digital technology and inform educators as to the educational value of all children's digital experiences prior to their arrival in kindergarten. Furthermore, in keeping with the theme of this special issue, the findings of this study 
suggest that, by engaging in current digital practices within the home, young children develop operational competencies with digital tools that may support their future civic engagement.

We begin with a description of the conceptual framework guiding the study. Specifically, we describe constructs from the sociocultural theory of literacy and assertions from literacy research on young children's use of digital technologies within the home that shaped our research questions and informed our analysis of the data.

\section{Perspectives}

We situate this study in a sociocultural theory of literacy. Working from within this framework, we understand literacy as a social practice, connected to beliefs, values, attitudes, and power structures. Since literacy practices are unobservable, they are inferred from observable literacy events mediated by texts (Barton \& Hamilton, 2000). Additionally, we draw from Vygotsky's (Wertsch, 1998; Vygotsky, 1978) notion of mediated social activity and understand that the digital texts with which the children engage serve as cultural tools that mediate their literacy learning. Within individual literacy events, adults in turn mediate these texts by using multiple modes (Kress, 1997) in order to scaffold (Rogoff, 1990) the children's engagement with the tool and text, or by transferring through modeling (Gregory, Ruby, \& Kenner, 2010) the knowledge and/or skills related to the child's use of the tool. Learning is visible through the children's changing participation in the event over time (Lave \& Wenger, 1991).

Although sociocultural researchers have documented children using digital tools in the home for learning and for entertainment purposes (e.g., Davidson, 2009; Marsh, 2004; Marsh, Yamada-Rice, Bishop, et al., 2015; O’Mara \& Laidlaw, 2011), much of the literature on pre-school aged children's experiences with digital technologies in the home prior to their entry into kindergarten stems from three studies situated in Scotland ${ }^{\mathrm{i}}$. The studies took place between 2003 and 2011. Data were collected primarily during home visits with approximately 54 case-study families. The families were roughly divided along household income. All families spoke English and had at least one pre-school aged child. Primary data collection methods included interviews and observations. Additional data were collected through surveys distributed to multiple families whose children attended pre-schools in four local authorities, from interviews with primary school teachers, and from an expert forum of key policymakers and practitioners.

From our review of the literature emanating from these three studies, we identified the following assertions regarding young children's digital literacy experiences: (a) Young children encounter a range of digital technologies at home (Plowman, McPake, \& Stephen, 2010; Plowman, Stevenson, Stephen, \& McPake, 2012), (b) the link between parents' own experiences with technology and the opportunities they offer their children in the home is stronger than is the link between a family's economic status and the children's access to digital technology (Plowman et al., 2010), (c) children develop basic levels of competence in multiple areas of learning as they engage with digital technologies (McPake, Stephen, Plowman, Sime, \& Downey, 2005; Plowman, McPake, \& Stephen, 2008), and (d) the method of transfer of knowledge and skills between children and adults varies (Plowman et al., 2008; Stephen, Stevenson, \& Adey, 2013). 
Data informing this body of literature were drawn from English-speaking participants who differed in economic status (i.e., disadvantaged, having a household income below $£ 20 \mathrm{k}$ pa, or advantaged, having a household income of over $£ 20 \mathrm{k} \mathrm{pa}$ ), and in the level of technology within the home (i.e., low technology, owning fewer digital tools such as a computer with Internet access, mobile phone, etc., or high technology, owning a computer with Internet access, a mobile phone, etc.). Our aim is to build on these assertions by describing the nature of the digital experiences in the homes of young children from diverse backgrounds. Drawing on data from two separate ethnographic case studies, our goals are to present descriptions of digital tool use within the homes and highlight both the differences and similarities between the young children's experiences. In keeping with our research questions, we only included observations of children engaging with tools that allowed them to access texts. Drawing from Purcell-Gates, Perry, and Briseño (2011), we understand texts as having a type or genre (e.g., activity/word puzzle, animated cartoon) and a physical form (e.g., computer, smart phone). Since the focus of our analysis was on texts displayed electronically, we also understand texts as having a digital form (e.g., educational software page, video sharing webpage).

\section{Positioning of Researchers}

We, Nicola and Laura, entered into our respective research as doctoral candidates working in the field of family and early literacy. We are both white, English-speaking females of European descent. Nicola worked in the community, first as a researcher, then as a volunteer for the family literacy program. Prior to entering her doctoral program, Nicola was a classroom teacher and a literacy coach. Laura previously worked as a classroom teacher and Early Literacy Specialist. Zipporah is a member of the Karen refugee community. She arrived in Canada in the fall of 2006. Prior to her arrival in Canada, she worked as a principal in a post-10 school in one of the refugee camps. She is currently employed as a multicultural worker with the local school district. She speaks both Karen and English. In this section, we presented the perspectives that informed this paper. Next, we outline the research methodology of the two larger studies from which we drew data and discuss how we analyzed the data in order to answer our research questions.

\section{Methodology}

For this paper, we draw on data we collected during two separate ethnographic case studies examining the home literacy practices of pre-school aged children in and around a large urban centre in western Canada. The first study took place over 15 months. The primary participants were three Karen mothers and their 4-year old children. The Karen are an ethnic group living in South East Asia with their own distinct language and culture. For the past 60 years, they have been engaged in a civil war against the Burmese military regime for autonomy and cultural rights. This conflict has resulted in many of the Karen fleeing their villages and seeking refuge in camps along the Thai-Burma border, where some have remained for up to 20 years. In 2005, Canada began to accept applications from Karen families through a United Nations' program. Communities within western Canada welcomed the first families in 2006. The three mothers were part of this group of refugees. Their first language is Karen. The children, two girls and one boy, were all born in Canada. Although their first language was Karen, they choose to communicate primarily in English.

Nicola collected data over a period of 15 months in the homes, community, and in 
all ten sessions of a bilingual family literacy program, Parents as Literacy Supporters (PALS) in Immigrant and Refugee Communities. Data collection methods included semistructured and informal interviews ${ }^{\mathrm{ii}}$ with each of the three focal mothers and participant observation of the three families engaged in literacy events in the three contexts. Nicola transcribed all field notes and interviews in English and uploaded the transcripts to the qualitative software, Atlas Ti. She identified and coded individual literacy events for setting, type of event (e.g., reading, writing), participants, role of participants, and tools (e.g., artifacts, language, actions). She displayed the coded field notes in output tables. Nicola repeatedly read the information in each output table to identify patterns, which she then discussed with Zipporah in order to clarify her interpretations. Additionally, as a form of member check, both Nicola and Zipporah met with the mothers to orally review the findings.

The second study took place in the homes of the participants over a period of 12 months. The participants were two white, middle-class, English-speaking families. The first family consisted of a single mother and her 4-year old daughter. The second was a 2parent family with twin 5-year old children (male and female). Laura conducted semistructured interviews with each mother and carried out monthly observations of the children in their homes, with each visit lasting approximately 2 hours. She also collected artifacts including photographs, drawings, and videos. Laura audio-recorded each semistructured interview and made field notes during each of the visits. She transcribed all interviews and field notes on the computer. Using the comment function of Microsoft Word, she coded individual literacy events for type of event (e.g., reading, writing, play), participants, role of participants, and the tool used (print or digital). She then read through the data and looked for patterns.

For this paper, we drew from the transcribed field notes of observations of the children in both studies engaging in literacy events within the homes and from the English transcriptions of the semi-structured interviews with the focal mothers. Nicola and Laura read through the field note transcripts together and identified all literacy events involving digital tools. Nicola then coded each event for who was participating and for their role in the event, how the event was arranged, the digital tool used in the event, and the digital texts mediating the event. Each coded event was displayed in an excel table. Nicola and Laura read through the tables and looked for patterns as they related to the research questions. We then read through the transcripts of the interviews to confirm patterns. Additionally, Nicola reviewed findings relating to the three Karen children with Zipporah. In the next section, we present findings resulting from this analysis of the data.

\section{Findings}

Our analysis of the data revealed the following findings: a) The children all had access to digital tools (e.g., desktop computer, smart phone, etc.) within the home, b) all the children used digital tools to access similar digital texts (e.g., animated cartoons, digital storybooks, word games and puzzles, etc.), and c) the children initiated individual events with parents or other adults providing varying degrees of assistance when needed. In this section, we present a sample of the data that supports these findings.

\section{Access to Digital Tools}

We observed digital tools in common areas (e.g., living room, family room) in all 
of the homes in which we visited. However, the type of tool to which the children had access varied. In general, the young Karen children had physical access to older forms of technology including computers, either desktop or laptop, and a television. Two of the Karen families had smartphones and one had a tablet. Two of the families had DVD players, while one had a video cassette player. By the end of the data collection period, one family had upgraded to a large flatscreen TV complete with a gaming console. In contrast, the children from the middle-class families had physical access to a larger variety of digital tools including smartphones, tablets, laptop computers, and electronic keyboards. One of the middle-class families had a LeapPad device.

Although most of these digital tools were physically accessible to the children, the children may not have engaged in activities with them. For example, one of the mothers in the first study had a smart phone and tablet. Throughout the data collection period of her study, Nicola did not observe the child engaging in activities on either of these digital devices. Moreover, parents in both studies controlled the children's access to tools by setting limits on the children's use of the digital tool or by password protecting devices. For example, Hser Paw ${ }^{\mathrm{iii}}$, one of the focal mothers in the first study, shared that her children knew that they were only allowed to watch or listen to one story or three songs in one session at the computer (Field notes, February 26, 2014). Similarly, Sarah, one of the mothers in the second study, indicated that her children usually accessed digital texts in the company of or in proximity to a parent. She said, "It's always with me or my husband. Sometimes, I'll leave them and then just like listen to hear what they've picked up, because they'll sometimes pick their own programming. But they also have some parameters from me" (Sarah, interview, March 31, 2015). Finally, during numerous visits within the home, Nicola observed one focal child's inability to access animated cartoons on the family's laptop since the father regularly changed the password.

\section{Accessing Digital Texts}

We observed all the children using certain digital tools (e.g., computer, television, smart phone) to access similar texts (e.g., cartoons, music videos, games) within the home. In some cases, the texts being accessed appeared to entertain the child. For example, the children watched cartoons and movies, sang along with music videos, made videos, and played games. They accessed animated cartoons through video sharing webpages on the computer or through cable cartoon channels, and television shows and music videos through video streaming apps on smartphones and tablets. Two of the children in the second study accessed a game through an app on a smartphone.

In one instance, a male, middle-income participant accessed a website (with his mother) that was associated with a magic kit he had received as a Christmas gift. The website was an extension of the physical magic kit and allowed the child to watch illusions performed by a magician. As well, the website contained information about the company and other magic tricks children could learn to master. Interestingly, one of the young Karen children accessed cartoons in other languages, specifically Chinese ${ }^{\mathrm{iv}}$. She also accessed music videos that showcased Burmese and Thai singers performing songs in multiple languages.

We also observed the children access texts specifically designed to mediate their learning, in particular, their learning about literacy in English. Unlike the texts accessed for entertainment purposes, these texts were in English only. For example, the children 
accessed activity or word puzzles, digital storybooks, and children's music videos through educational software pages on the computer or on the LeapPad device and through educational software apps on a tablet. These educational webpages and apps provided the children with opportunities to learn about science, build words, colour images, read and listen to stories, and sing nursery rhymes in English.

\section{Children as Initiators}

In general, we observed the children initiate these individual digital events. The role of the parent or adult was to provide assistance when needed. The type of assistance provided depended on the digital tool being used. For example, Nicola observed the following event during a visit with one of the focal children in her study:

Claire initiated a Google search and began to type the words 'skip to my lou' into the search engine. Her mother assisted by spelling the words for her in English. When a website came up, Claire indicated that it was the wrong version of the rhyme. Zipporah went over and called up the correct website on her behalf. (Field notes, April 17, 2013)

In this example, the child, Claire, had been playing a math game on the computer. As was customary in the Karen culture, her mother, Hser Paw was visiting with her guest, (Zipporah), in Karen. At one point, Nicola heard her mention the song, "Skip to my Lou". Claire must have heard it as well since, using the mouse, she promptly exited her game and began a search for the website showing children singing along with this song. Hser Paw assisted Claire by spelling out the words in English as Claire typed them into the search engine. When the search resulted in the wrong webpage being displayed, Zipporah provided assistance by returning to the search results page and selecting another webpage on Claire's behalf.

Laura observed a similar form of engagement between a mother and her son during a home visit. She made the following entry in her field notebook:

Luke picked up the iPad from the couch and sat on the floor. He asked mom if he could look at a science website. Mom sat down on the floor beside him and they leaned the iPad on the couch as though the couch were a table. Luke touched the Safari icon at the bottom of the iPad screen and allowed the web browser to load. He touched the website search bar and found the appropriate website. A "child-friendly" science website loaded. (Field notes, April 9, 2015)

In this event, the focal child, Luke, asked his mother for permission to access a science website on the tablet. In contrast to Hser Paw, her role in the event was simply to assist Luke in positioning the tablet on the floor. Luke then accessed the website on his own, first by touching the digital icon to launch the web browser and then by selecting the website from the website search bar.

At other times, the children accessed the digital text without asking for assistance. Nicola made the following entry in her field notebook: 
The television in the corner was on. It was a large flat screen TV. Throughout my visit, Sam took the remote control and changed the channel. In the process of changing the channel, he said the name of the individual digit in English as he pressed the button. (Field notes, April 19, 2013)

In this example, Sam was able to operate the remote control in order to change the television channel. Not only did he understand the function of the numbers on the remote control, he also demonstrated his numeracy skills by providing the label for each of the selected digits.

At other times, both Nicola and Laura were called upon to assist a child with aspects of the digital tool the child had yet to master. For example, during one visit, Claire indicated to the first author that she wanted to change websites. Nicola asked Claire for the name of the website she wanted to access. She typed the search term into the search engine page and, using the mouse, selected the site from the search result list. She then asked Claire for the name of the activity she wished to access. Claire indicated that she wanted to listen to a digital story. Using the mouse, the first author selected the digital icon from the website's homepage to select the story.

In contrast, during one visit, rather than asking for assistance to access a text, Luke asked Laura to assist him in creating a digital video. The following description is taken from the Laura's field notebook:

Luke asked if I could make videos on my phone. I explained I could and showed him how the photograph app allowed users to change the size of the photograph (square, regular, or panorama) or record a video. Luke tells me to take a video of him dancing. He positions himself in front of the iPhone and tells me when to begin recording. He dances briefly on the spot and tells me to stop recording. He runs back to where I am seated on the floor and asks to see the recorded product. (Field notes, May 13, 2015)

This event was initiated when Laura engaged in a common social practice, using her phone to take a picture of Luke. When Luke saw the phone, he thought of making a video. Since the practice of making videos on a smartphone was new to Luke, Laura assisted first by explaining the process to Luke and then by recording Luke's dance. Immediately following this event, Laura assisted Luke in recording his sister, Leia, dancing. Luke proceeded to create seven very short (1-3 seconds in length) recordings on his own of his sister dancing.

In sum, all of the children had physical access to a variety of digital tools within the home. While the types of tools to which the children had access varied (e.g., smartphones, tablets, LeapPads, computers, televisions), the children initiated the use of these tools to access similar genres of digital texts (e.g., animated cartoons, educational games, digital storybooks) and engage in similar events (e.g., watching cartoons and videos, colouring pictures and assembling puzzles, listening to stories, playing games). Although the children were the initiators of the events, in some cases, they had yet to develop the competence or understanding needed to operate aspects of the digital tool. Parents and other adults responded by providing assistance when needed. We now discuss these findings in relation to the literature on young children's digital experiences in the home. 


\section{Discussion}

In their study investigating the impact of socio-economic disadvantage on preschool children's development of competencies in information and communications technology, McPake et al. (2005) concluded that, although family income likely affected the amount and quality of equipment within the home, families often found ways to get those digital tools that best supported their cultural practices. For example, some of their case study families bought equipment such as desktop computers from second-hand stores or swapped items with friends and neighbours. Our findings support this conclusion. In contrast to the middle-class children in the second study whose parents had the economic resources to purchase newer forms of technology or who received digital devices as gifts, the Karen families arrived in Canada as permanent residents with limited economic resources. Thus, many of the digital tools within the homes of the Karen children were donated and included older forms of technology such as desktop computers and televisions.

Plowman et al. (2010) reviewed arguments relating to the technologisation of childhood. Drawing on data from one of the larger studies (see above), they found a strong link between the young children's digital opportunities in the home and the parents' own experiences with digital technology. Although the availability of digital tools in the homes of the Karen families in the first study may have been constrained by economic factors, in keeping with the findings of Plowman, et al., we argue that the families' choice of digital tools reflected their social and cultural practices. Many of the Karen adults were born in Karen villages in Burmav ${ }^{v}$. In Karen villages, it was common for one resident to own a television. Due to the remoteness of the villages, the television was used to play videos. Younger members of the resettled refugee community were born in the refugee camps. While growing up, many of them had access to desktop computers in the camps. At the time of the first study, Nicola observed that all three of the Karen families had a television and a desktop computer in their home. These digital tools mediated such cultural practices as watching animated cartoons and cultural videos. Other research within resettled Karen populations identified additional digital literacy practices. For example, besides using the computer for entertainment purposes, Quadros and Sarroub (2016) found that, within the home, the Karen women participating in their study used the computer as a resource for learning and for finding a job in their new community. Additionally, Gilhooly and Lee (2014) and Omerbašič (2015) found the Karen teens in their studies used digital tools (e.g., desktop computers) in the home and community to connect with Karen teens around the world in order to help them overcome feelings of isolation in their new community.

In contrast, the middle-class parents in the second study were born and raised in Canada. Although families with similar socio-economic circumstances foster young children's development and learning differently (Stephen, Stevenson, \& Adey, 2013), within the homes of the middle-class families participating in the second study, digital tools such as laptop computers, smart phones, and tablets, mediated various social and cultural practices. In both homes, the parents placed an emphasis on using technology and digital tools for learning, whereby they used digital tools to access information and scaffold their children into this practice. For example, the parents used Google to extend information about something read in a book or to search websites on a particular topic. Netflix was a source of family time entertainment. The parents accessed movies and television shows which they then watched with their children. For instance, Sarah discussed how eager she was to watch the Star Wars franchise with her children, as they were movies she and her 
husband had enjoyed when they were younger. Sociocultural researchers have documented children using digital tools to mediate similar digital practices within the home (e.g., Davidson, 2009; O’Mara \& Laidlaw, 2011; Marsh, Yamada-Rice, Bishop, et. al., 2015).

Furthermore, Plowman et al. (2010) found parents were aware of potential problems associated with digital technology, but they believed the risk to be low if the children engaged with digital tools in moderation and under a parent's supervision. We found that, regardless of economic status, mothers in both studies shared similar concerns regarding their children's screen time and that these concerns prompted them to limit their children's access to digital tools within the home. For example, as a member of the resettled Karen community, Zipporah shared that many of the Karen parents in the first study had concerns regarding their children's social skills. The parents set limits on their children's use of digital tools in order to encourage them to interact with other children in formal and informal settings. Similarly, a mother participating in the second study had concerns about her children's cognitive development. She said, “ ... kids really need to be hands-on, like learning through their senses and that they need to move around. So as much as possible, like in those early months and years, try not to have that stuff around ..." (Sarah, interview, March 31, 2015). Finally, one parent was concerned about her child's physical fitness. Laura recorded this concern in her field notes. She wrote, "Lindsay shared with me that she aims on weekends to spend time outside or at local recreation centre so that she and Belle can be physically active, rather than spend the time at home doing sedentary activities (Field notes, March 29, 2015). Thus, even though children had access to different types of digital tools, this access was universally limited due to parental concerns over screen time.

Interestingly, in both our studies, the parents' concerns appear to have been shaped in part by the mothers' involvement in parental discussion groups. For example, the Karen parents all participated in a bilingual family literacy program. One session of the program focused on children and computers. During this session, the English-speaking facilitators shared with the Karen parents common concerns regarding the effects of prolonged screen time on young children. Similarly, Sarah told Laura that she participated in an online forum for parents and regularly received emails regarding a child's healthy development. Thus, although Alper (2011) found that families from middle to higher socioeconomic statuses might not fully support new media use "due to 'moral panics' regarding popular culture and digital technologies" (p. 180), our findings suggest that parental concerns are socially constructed and are not specific to socio-economic status.

Irrespective of the digital tool, in all of the homes, the children engaged in meaningmaking activities, such as creating texts, singing along with videos, and watching cartoons. Plowman et al. (2008) identified levels of competencies in four main areas of learning with technology within the home including extending knowledge of the world (e.g., developing early literacy and numeracy) and understanding cultural roles (e.g., the roles technology plays in family life). Drawing from a sociocultural perspective of learning, we recognize young children as experienced meaning-makers, making meaning from what is at hand (Kress, 1997). We understand all of the children in this study to be meaning-makers. For example, by using a smartphone to make videos of his sister, Luke created his own digital text, one which he and his sister then enjoyed together. By singing along with Karen music videos on the computer, Emma developed her ability to speak Karen and strengthened her Karen identity (Gilhooly \& Lee, 2014; Omerbašič, 2015). By watching an animated 
program on her mother's tablet, Belle was inspired to extend the activity to include drawing scenes from the show on paper.

In addition to promoting a child's meaning-making, McPake et al. (2005) and Plowman et al. (2008) identified another area of learning with technology in the home, acquiring operational skills. Specifically, through their engagement with digital technologies, children acquire operational skills including an understanding of the functions of the various attributes of the tool (e.g., the mouse, the touch screen) and the ability to operate them. We found that the children in our two studies were acquiring numerous competencies that allowed them to independently operate the digital tools available to them in their homes. For example, Claire used the mouse in order to select a website from the search result list. Luke tapped a digital icon on a touch screen in order to access a webpage. Sam used a remote control in order to change the television channel.

Finally, Stephen et al. (2013) found that parents support their children's learning directly by scaffolding their interactions verbally (e.g., providing suggestions) or through physical actions (e.g., pointing) and that the type of interaction depends on the digital tool. Our findings also suggest that the type of assistance parents or other adults provide directly depends on the digital tool being used. For example, in the homes where the primary tool was a desktop or laptop computer, the children needed assistance in accessing educational webpages since their engagement with these types of texts was mediated by other forms of activities (e.g., typing in search terms in English, reading search result lists in English). Similarly, in homes where children engaged with newer forms of digital technology including smart phones and tablets, the children needed assistance in accessing app-based activities and games through digital icons displayed on the screen. Furthermore, like Stephen et al. (2013), we also found that family interactions, specifically the demands placed on parents' time, indirectly supported the children's learning. For example, both of the mothers in the second study told Laura that, in order to allow them time to complete their household chores, they encouraged their children to use a device individually.

We believe the finding that the assistance children require depends on the digital tool being used is of particular importance to educators. Teachers need to be aware of the children's developing competencies with different digital tools and understand that all children may need some direct assistance in operating digital devices. For example, children familiar with older forms of technology (e.g., desktop computers) might not be as familiar with accessing activities through digital icon texts as are those children who have access to these types of tools within the home. Similarly, those children who were accustomed to accessing texts through digital icons may not be as familiar with initiating searches and selecting from lists of search results. Thus, regardless of the tool, children are learning operational competencies upon which teachers can build in the classroom. As O'Hara (2011) points out, we should shift our focus in the classroom away from talking about children's unequal access to equipment and towards assisting them in "using ICT [information and communications technology] to live well in contemporary society" (p. 222).

\section{Conclusions}

This study contributes to the literature on young children's techno-literacy practices by describing the digital activity of children from culturally, linguistically, and economically diverse homes. Specifically, this study suggests that, through their 
interactions with digital tools within the cultural and economic landscapes of their home, young children develop operational competencies that facilitate their accessing digital texts to support their learning. And, although parents provide assistance when needed, because of concerns regarding screen time, parents also limit their children's access to digital tools and digital texts within the home regardless of their socioeconomic status. Thus, rather than focusing on what makes them divided, this study conceptualizes the digital experiences of young children in terms of their similarities.

In keeping with the theme of this special issue, we also suggest that, through their engagement in digital literacy practices within the home, the children are developing operational competencies that may allow them, as they grow older, to use digital tools to become informed about issues in their community, to connect with others from within the community, and to provide them with a platform to share their ideas with other members of the community. In other words, by engaging in digital practices within the home, young children from culturally and economically diverse homes have the opportunity to develop into capable and committed $21^{\text {st }}$ century citizens.

We acknowledge a number of limitations that prevent the generalizability of these findings. First, data were collected from five families representing two cultural groups. Furthermore, two of the participants in the second study were siblings. Future research should include collecting data within the homes of families from multiple cultural and linguistic communities who vary in terms of family composition. Second, due to the Nicola's inability to speak Karen, any conversations that took place between the children and their mothers in Karen needed to be translated into English either by the children or by Zipporah who was acting as Nicola's research assistant. Finally, we acknowledge that our presence in the homes affected the children's usual engagement in activities. However, prolonged engagement and persistent observation should have helped ameliorate or overcome these potential risks.

\section{Acknowledgements}

The first author is appreciative of the financial support of The Social Sciences and Humanities Research Council. All three authors are grateful to the families for their participation in these two studies and for welcoming us into their homes. We confirm that the two studies from which we drew the data observed the Tri-Council Ethical Guidelines or appropriate guidelines related to the ethical conduct of research.

\section{References}

Alper, M. (2011). Developmentally appropriate New Media Literacies: Supporting cultural competencies and social skills in early childhood education. Journal of Early Childhood Literacy, 13(2), 175-196.

Barton, D., \& Hamilton, M. (2000). Literacy practices. In D. Barton, M. Hamilton, \& R. Ivanic (Eds.), Situated literacies: Reading and writing in context (pp. 7-15). London: Routledge.

Davidson, C. (2009). Young children's engagement with digital texts and literacies in the home: Pressing matters for the teaching of English in the early years of schooling. English Teaching: Practice and Critique, 8 (3), 36-54.

Gilhooly, D., \& Lee, E. (2014). The role of digital literacy practices on refugee resettlement. Journal of Adolescent \& Adult Literacy, 57, 387-396. 
Gregory, E. (2001). Sisters and brothers as language and literacy teachers: Synergy between siblings playing and working together. Journal of Early Childhood Literacy, 1, 301-322.

Gregory, E., Ruby, M., \& Kenner, C. (2010). Modelling and close observation: Ways of teaching and learning between third generation Bangladeshi British children and their grandparents in London. Early Years, 30, 161-173.

Gutnick, A., Robb, M., Takeuchi, L., \& Kotler, J. (2011). Always connected: The new digital media habits of young children. Retrieved from http://www.joanganzcooneycenter.org/wpcontent/uploads/2011/03/jgcc_alwaysconnected.pdf

Heath, S. (1983). Ways with words. Cambridge, MA: Cambridge University Press.

Kress, G. (1997). Before writing: Rethinking the paths to literacy. London, UK: Routledge.

Lave, J., \& Wenger, E. (1991). Situated learning: Legitimate peripheral participation. New York, NY: Cambridge University Press.

Marsh. J. (2004). The techno-literacy practices of young children. Journal of Early Childhood Research, 2(1), 51-66.

Marsh J., Plowman L., Yamada-Rice D., Bishop J., Lahmar J., Scott F., Davenport A., Davis S., French K., Piras M., Thornhill, S. (2015). Exploring Play and Creativity in Pre-Schoolers' Use of Apps: Technology and Play. Economic and Social Research Council. Available at: http://www.techandplay.org/tap-media-pack.pdf

McPake, J., Stephen, C., Plowman, L., Sime, D., \& Downey, S. (2005). Already at a disadvantage? ICT in the home and children's preparation for primary school. ICT Research Bursaries 2004-Final Report. Retrieved from http://www.york.ac.uk/res/e-society/projects/3/already_disadvantage.pdf

O'Hara, M. (2011). Young children's ICT experiences in the home: Some parental perspectives. Journal of Early Childhood Research, 9(3), 220-231.

O’Mara, J., \& Laidlaw, L. (2011). Living in the iworld: Two literacy researchers reflect on the changing texts and literacy practices of childhood. English Teaching: Practice and Critique, 10(4), 149-159.

Omerbašič, D. (2015). Literacy as a translocal practices: Digital multimodal literacy practices among girls resettled as refugees. Journal of Adolescent \& Adult Literacy, 58, 472-481.

Plowman, L., McPake, J., \& Stephen, C. (2008). Just picking it up? Young children learning with technology at home. Cambridge Journal of Education, 38(3), 303319.

Plowman, L., McPake, J., \& Stephen, C. (2010). The technologisation of childhood? Young children and technology in the home. Children \& Society, 24, 63-74.

Plowman, L., Stevenson, O., McPake, J., Stephen, C., \& Adey, C. (2011). Parents, preschoolers and learning with technology at home: Some implcations for policy. Journal of Computer Assisted Learning, 27 (4), 361-371.

Plowman, L., Stevenson, O., Stephen, C., \& McPake, J. (2012). Preschool children's learning with technology at home. Computers \& Education, 59, 30-37.

Purcell-Gates, V. (1996). Stories, coupons, and the "TV Guide:" relationship between home literacy experiences and emergent literacy knowledge. Reading Research Quarterly, 31, 406-428. 
Purcell-Gates, V., Perry, K., \& Briseño, A. (2011). Analyzing literacy practice: Grounded theory to model. Research in the Teaching of English, 45(4), 439-458.

Quadros, S., \& Sarroub, L. (2016). The case of three Karen refugee women and their children: Literacy practices in a family literacy context. Diaspora, Indigenous, and Minority Education, 10, 28-41.

Rideout, V. (2011). Zero to eight: Children's media use in America. Retrieved from https://www.commonsensemedia.org/research/zero-to-eight-childrens-media-usein-america

Rogoff, B. (1990). Apprenticeship in thinking. New York, NY: Oxford University Press.

Stephen, C., Stevenson, O., \& Adey, C. (2013). Young children engaging with technologies at home: The influence of family context. Journal of Early Childhood Research, 11(2), 149-164.

Taylor, D. (1983). Family literacy: Young children learning to read and write. Portsmouth, NH: Heinemann.

Taylor, D., \& Dorsey-Gaines, C. (1988). Growing up literate: Learning from inner-city families. Portsmouth, NH: Heinemann.

Vygotsky, L. (1978). Mind in society. Cambridge, MA: Harvard University Press.

Wertsch, J. (1998). Mind as action. New York: NY: Oxford University Press.

Wohlwend, K. (2013). Literacy playshop: New literacies, popular media, and play in the early childhood classroom. New York: Teacher's College Press.

\section{Author Biographies}

Nicola Friedrich is a Post Doctoral Fellow in the Department of Curriculum, Teaching, and Learning at the Ontario Institute for Studies in Education. She is currently participating in the NOW Play project to assess and support young children's oral language and writing development through play in classrooms and early childhood programs in northern communities. Contact: n.friedrich@utoronto.ca

Laura Teichert is a PhD candidate in the Department of Language and Literacy Education at the University of British Columbia. Before returning to studies, she worked in elementary education and as an Early Literacy Specialist. Her research interests are in the areas of early literacy and family literacy, particularly young children's digital engagement and families' digital literacy practices in their homes.

Zipporah Devadas is a Multicultural Worker with British Columbia School District \#35 where she supports the literacy needs of Karen families and their children in the school and community.

\section{Endnotes}

\footnotetext{
${ }^{\mathrm{i}}$ See Plowman, Stevenson, McPake, Stephen, \& Adey (2011) for a full description of the three studies.

ii During each interview, Nicola asked questions in English. Zipporah translated the interviewer's questions into Karen. Additionally, Zipporah translated the interviewee's response into English. iii All names are pseudonyms.
} 
iv The child's mother described this event to Nicola during one of her visits within the home. The mother did not provide the specifics of the event, such as if the language of the cartoon was Cantonese or Mandarin.

${ }^{\mathrm{v}}$ In 1989, the ruling military regime changed the name from Burma to Myanmar. Canada does not recognize the name Myanmar and continues to refer to the country as Burma. 